\title{
Clinico-pathological correlations of childhood glomerular disease in Eastern India
}

\author{
Pawan Pradeep Mutalik ${ }^{1}$, Subal Kumar Pradhan ${ }^{2}$, Bikrant Kumar Prusty ${ }^{1}$, Kedar Das ${ }^{3}$, Saroj Kumar \\ Satapathy ${ }^{4}$
}

Sri Lanka Journal of Child Health, 2015; 44(1): 31-37

\begin{abstract}
Background: Histopathological examination of renal biopsy has an important role in establishing glomerular disease in children.

Objective: To describe and correlate the types of glomerular diseases reported in native kidney biopsy and their clinical presentations.
\end{abstract}

Method: This retrospective and descriptive study was conducted from December 2009 to December 2013 at the Department of Paediatrics, SVPPGIP \& SCB Medical College, Cuttack, Odisha, India. A total of 142 renal biopsies were performed in 140 children aged 6 months to 14 years. Their demographic data, indication for renal biopsy and histological diagnosis were analysed and correlated with clinical presentations in the study.

Results: In $136(97.1 \%)$ of 140 children, the renal histopathology revealed glomerular diseases. The male to female ratio was $1.5: 1$. The most frequent types of biopsy-proven renal diseases were: Minimal Change Disease 47 (33.5\%), Focal Segmental Glomerulosclerosis 29 (20.7\%), IgA nephropathy 21 (15\%), Lupus nephritis 11 (7.8\%) and Post-streptococcal glomerulonephritis 8 (5.7\%). Nephrotic syndrome was the most common glomerular disease 106 (77.9\%).

Conclusions: In our study, Minimal Change Disease was the most common biopsy proven glomerular disease and nephrotic syndrome was the most frequent clinical presentation. The best clinico-pathological correlation was seen with lupus nephritis cases.

(Keywords: Clinico-pathological correlation; children; Minimal Change Disease; glomerular disease; renal biopsy)

${ }^{1}$ Post Graduate, ${ }^{2}$ Assistant Professor, ${ }^{3}$ Associate Professor, ${ }^{4}$ Professor, Department of Paediatrics, SVPPGIP \& SCB Medical College, Utkal University, India

(Received on 24 April, 2014: Accepted after revision on 20 June 2014)

\section{Introduction}

Glomerular disease can present as nephrotic syndrome (NS), nephritic syndrome, rapidly progressive renal failure, acute kidney injury (AKI), chronic kidney disease (CKD) as well as isolated proteinuria or haematuria ${ }^{1}$. Renal biopsy will help in making early diagnosis and instituting the right medications promptly ${ }^{2}$. The pattern of glomerular diseases may differ in different population groups ${ }^{3}$. One pattern of clinical presentation may be associated with different glomerular diseases ${ }^{4}$. Minimal Change Disease (MCD) is the most common histological sub-type of nephrotic syndrome in children ${ }^{5}$. In one of the largest reports of 6469 biopsies with glomerular disease (GD) in adults from the University of North Carolina, focal segmental glomerulosclerosis (FSGS) was the most common GD (14.22\%) followed by membranous nephropathy (MN) $(13.09 \%)$. However, there is a variation in the prevalence of the type of GD according to geographical location and race of the study population ${ }^{6}$. Estimates on the annual incidence of NS range from $2-7$ per 100,000 children, and prevalence from $12-16$ per $100,000^{7}$. MCD is the most common cause of NS in children, the other sub-types being FSGS and MN. MCD constitutes about $85 \%$ of cases in young children ${ }^{8}$.

A large study on spectrum of glomerular diseases has not taken place in children anywhere in the world, including India. Hence, we decided to undertake a retrospective review of all the native kidney biopsies in children done in our tertiary care paediatric referral hospital with an aim of compiling and analysing various glomerular diseases and their clinical presentations.

\section{Method}

This study was conducted in children aged 6 months to 14 years from December 2009December 2013 at the Department of Pediatrics, SVPPGIP and SCB Medical College, Cuttack, Odisha, India. A total of 142 renal biopsies were performed in 140 children after getting written consent from parents or legal guardians. The ultrasound-guided percutaneous renal biopsy specimens were obtained by automated biopsy gun. The indications of biopsy were unexplained AKI or 
renal failure, Lupus nephritis (LN), steroid resistant nephrotic syndrome (SRNS), children with atypical features of NS such as gross haematuria or hypertension, age group less than one year and steroid dependent nephrotic syndrome (SDNS) or frequently relapsing nephrotic syndrome (FRNS) before starting any calcineurin inhibitors (CNI). The necessary demographical, clinical and laboratory data at the time of presentation were noted. Histopathological evaluation of the biopsy specimens was done by light microscopy (LM) and immuno-fluorescence (IF) and these were documented in original biopsy forms and then retrieved for the purpose of this study. IF staining was done with antibodies against IgG, IgM, IgA, $\mathrm{C}_{3}, \mathrm{Clq}$ and other markers as indicated. The data was stored and analysed by Microsoft Excel software. Standard definitions of the disease, investigation protocols and treatment responses were used as per the ISPN guidelines. The definitions used to assess the clinical course were as follows ${ }^{9,10,11}$.

NS: Oedema, nephrotic range proteinuria, hypoalbuminaemia (serum albumin $<2.5 \mathrm{~g} / \mathrm{dl}$ ), hyperlipidaemia (serum cholesterol $>200 \mathrm{mg} / \mathrm{dl}$ ).

Nephritic syndrome: haematuria, oedema, hypertension and varying degree of proteinuria.

Nephrotic range proteinuria: early morning urine protein is $3+/ 4+$ (on dipstick or boiling test), spot protein/creatinine ratio $>2 \mathrm{mg} / \mathrm{mg}$.

Haematuria: > 5 RBCs per high power field.

Hypertension: systolic or diastolic blood pressure exceeding 95th centile for age, gender and height.

Lupus nephritis: Hypertension, active urinary sediments, proteinuria, with or without nephrotic syndrome and raised serum creatinine levels in a patient with systemic lupus erythematosus (SLE). The International Society of Nephrology/Renal Pathology Society (ISN/RPS) classification of Lupus nephritis (LN) $)^{12,13}$ is as follows:
- Class I: Minimal mesangial LN - Normal glomeruli by LM, but mesangial immune deposits by IF

- Class II: Mesangial proliferative LN - Purely mesangial hypercellularity of any degree or mesangial matrix expansion by LM, with mesangial immune deposits with a few isolated sub epithelial or sub endothelial deposits by IF or electron microscopy (EM)

- Class III: Focal LN - Glomerulonephritis involving $<50 \%$ of all glomeruli

- Class IV: Diffuse LN - Glomerulonephritis involving $\geq 50 \%$ of all glomeruli. This class is divided into diffuse segmental (IV-S) LN when $\geq 50 \%$ of the involved glomeruli have segmental lesions, and diffuse global (IV-G) LN when $\geq 50 \%$ of the involved glomeruli have global lesions

- Class V: Membranous LN - May occur as pure membranous or combination with class III or IV

- Class VI: Advanced sclerotic LN - $290 \%$ of glomeruli globally sclerosed without residual activity

All this data was compiled and analysed using Microsoft Excel software.

Efficacy and adequacy of renal biopsy: The sample was adequate in the majority of biopsies with inadequate tissue in only 2 samples. In $35 \%$ samples the yield was between 5-10 glomeruli and in $65 \%$ glomeruli were $>10$.

\section{Results}

Out of 140 children, 136 (97\%) biopsies revealed glomerular diseases. Of the remaining 4 biopsies, 3 (2.14\%) cases had acute interstitial nephritis (AIN) and one case was found to have primary renal NonHodgkin's Lymphoma (NHL). The age and sex wise categorization is as presented in Table 1.

Table I: Age and sex wise categorization of renal biopsy findings

\begin{tabular}{|c|c|c|c|c|c|c|c|}
\hline \multirow{2}{*}{ Lesion } & \multicolumn{4}{|c|}{ Age groups of presentation } & \multicolumn{3}{c|}{ Sex } \\
\cline { 2 - 7 } & $\mathbf{6 M - 1 Y}$ & $\mathbf{2 - 5 Y}$ & $\mathbf{6 - 1 0 Y}$ & $\mathbf{1 1 - 1 4 Y}$ & Males & Females & \\
\hline Ig AN & 0 & 8 & 6 & 7 & 16 & 5 & 21 \\
\hline Ig MN & 0 & 7 & 0 & 0 & 5 & 2 & 7 \\
\hline LN & 0 & 1 & 3 & 7 & 6 & 5 & 11 \\
\hline MSPGN & 0 & 1 & 2 & 0 & 2 & 1 & 3 \\
\hline FSGS & 1 & 17 & 3 & 8 & 18 & 11 & 29 \\
\hline RPGN & 0 & 1 & 0 & 2 & 1 & 2 & 3 \\
\hline PSGN & 0 & 2 & 6 & 0 & 5 & 3 & 8 \\
\hline MCD & 1 & 28 & 12 & 6 & 26 & 21 & 47 \\
\hline CKD & 1 & 0 & 2 & 0 & 1 & 2 & 3 \\
\hline MPGN & 0 & 0 & 1 & 0 & 1 & 0 & 1 \\
\hline MN & 0 & 1 & 0 & 2 & 1 & 2 & 3 \\
\hline NHL & 0 & 0 & 1 & 0 & 1 & 0 & 1 \\
\hline AIN & 1 & 0 & 0 & 2 & 2 & 1 & 3 \\
\hline Total & 4 & 52 & 48 & 35 & 84 & 56 & 140 \\
\hline
\end{tabular}


The incidence rates of various histopathological sub-types are as in Figure 1.

\section{BIOPSIES}

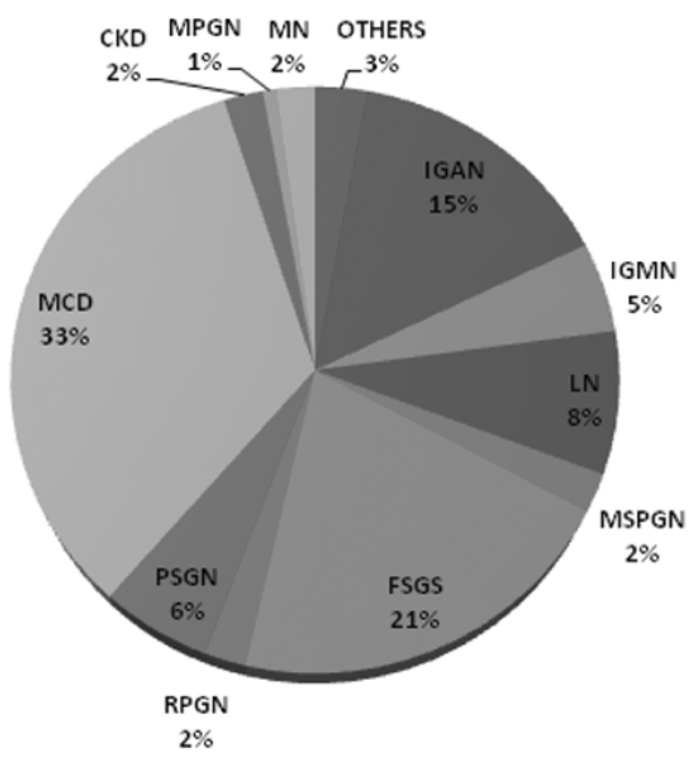

Figure 1: Pie chart showing the histopathological findings of various renal diseases in our study Note that the category 'others' includes AIN and NHL

The male to female ratio was $1.5: 1$ with $84(60 \%)$ being males and $56(40 \%)$ being females. The mean age was $6.31 \pm 3.75$ years with a range of 6 months-14 years. The youngest child was aged 6 months. There were 4 cases who presented with infantile NS. Thirty five (25\%) of these 140 were aged between 10-14 years. The most frequent types of biopsy-proven renal diseases were: MCD 47(33.6\%), FSGS 29(20.7\%), Ig AN 21(15\%), lupus nephritis 11(7.86\%), PSGN 8(5.71\%), Ig MN 7(5\%), CKD 3(2.14\%), RPGN 3(2.14\%), MSPGN $3(2.14 \%)$ and $\mathrm{MN} 3(2.14 \%)$. Only one case had MPGN. MCD, FSGS, LN, Ig MN and PSGN had almost equal incidence in males and females whereas Ig AN was predominantly seen in males in our study group. Both FSGS and MCD were most commonly seen in the age group of 2-5 years while LN was more commonly encountered in the 11-14 year age bracket. In 107 (78.7\%) children, nephrotic range proteinuria was seen, majority of them being due to MCD (Figure 2) and FSGS as depicted in Table 2.

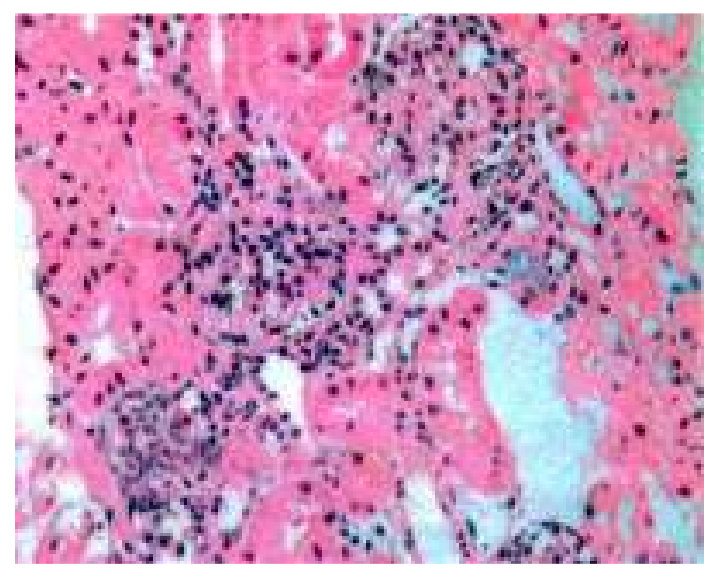

Figure 2: 2.5 year old male; light microscopy showing normal glomerular morphology suggestive of $M C D$

Table 2: Spectrum of glomerular diseases and their clinical presentations

\begin{tabular}{|c|c|c|c|c|c|}
\hline $\begin{array}{c}\text { Glomerular } \\
\text { Disease }\end{array}$ & Number & $\begin{array}{c}\text { Nephrotic } \\
\text { Proteinuria }\end{array}$ & $\begin{array}{c}\text { Non-nephrotic } \\
\text { range proteinuria }\end{array}$ & Haematuria & Hypertension \\
\hline MCD & 47 & 46 & 1 & 6 & 16 \\
\hline FSGS & 29 & 26 & 3 & 11 & 13 \\
\hline LN & 11 & 4 & 7 & 17 & 11 \\
\hline Ig AN & 21 & 18 & 3 & 4 & 2 \\
\hline Ig MN & 7 & 5 & 2 & 8 & 7 \\
\hline PSGN & 8 & 1 & 7 & 1 & 1 \\
\hline MSPGN & 3 & 2 & 1 & 3 & 3 \\
\hline MN & 3 & 3 & 0 & 1 & 1 \\
\hline RPGN & 3 & 1 & 2 & 0 & 3 \\
\hline MPGN & 1 & 0 & 2 & $63(46.32 \%)$ & $59(43.38 \%)$ \\
\hline CKD & 3 & 1 & $29(21.32 \%)$ & & \\
\hline Total & 136 & $107(78.68 \%)$ & & & 2 \\
\hline
\end{tabular}

$59(43.4 \%)$ children were hypertensive with 63 $(46.3 \%)$ children having haematuria at the time of biopsy. The most common clinical presentation was nephrotic syndrome in $106(77.9 \%)$ cases as shown in Table 3. 
Table 3: Correlation between glomerular disease and clinical presentation

\begin{tabular}{|l|c|c|c|c|}
\hline \multirow{2}{*}{$\begin{array}{c}\text { Glomerular } \\
\text { disease }\end{array}$} & $\begin{array}{c}\text { Nephrotic } \\
\text { syndrome }\end{array}$ & $\begin{array}{c}\text { Nephritic } \\
\text { syndrome }\end{array}$ & $\begin{array}{c}\text { Acute kidney } \\
\text { injury }\end{array}$ & $\begin{array}{c}\text { Chronic kidney } \\
\text { disease }\end{array}$ \\
\cline { 2 - 5 } & 47 & 00 & 00 & 00 \\
\hline MCD & 29 & 00 & 00 & 00 \\
\hline LSGS & 00 & 11 & 04 & 00 \\
\hline Ig AN & 18 & 03 & 00 & 00 \\
\hline Ig MN & 07 & 00 & 00 & 00 \\
\hline PSGN & 00 & 08 & 03 & 00 \\
\hline MSPGN & 02 & 01 & 00 & 00 \\
\hline MN & 03 & 00 & 00 & 00 \\
\hline RPGN & 00 & 03 & 03 & 00 \\
\hline MPGN & 00 & 01 & 00 & 03 \\
\hline CKD & 00 & 00 & 00 & 03 \\
\hline Total & $106(77.9 \%)$ & $27(19.9 \%)$ & $10(7.4 \%)$ & \\
\hline
\end{tabular}

In our study, MCNS was the most common glomerular disease and Lupus nephritis had the best clinico-pathological correlation. Hence, they need some elaboration here. All 47 MCNS cases requiring renal biopsy presented as nephrotic syndrome with $46(98 \%)$ children having nephrotic range proteinuria, $6(12.7 \%)$ having haematuria and $16(34 \%)$ having hypertension at presentation. 23 $(49 \%)$ of them had a steroid resistant course, 17 $(36.2 \%)$ cases had a steroid dependent course with $7(14.9 \%)$ children having frequently relapsing course. Hypertension, proteinuria and haematuria were present in all cases of LN which indicated severe proliferative glomerular lesions and which was subsequently reflected in renal histopathology.

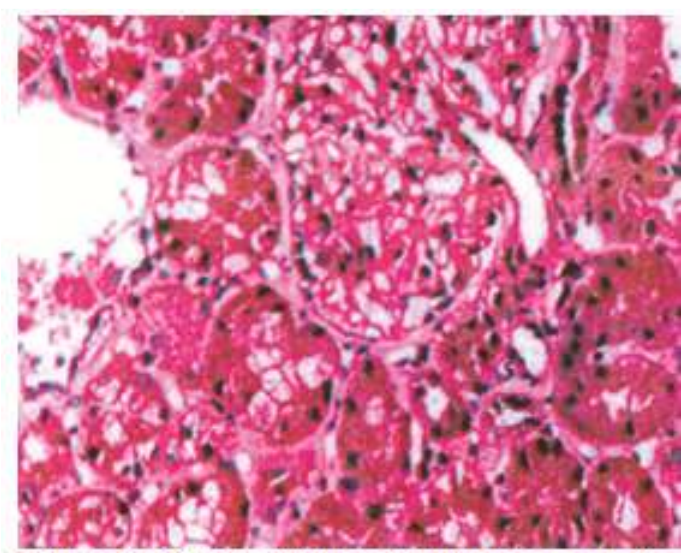

Figure 3: 13 year old male; light microscopy of same patient showing diffuse mesangial hypercellularity. Interstitium shows moderate diffuse lymphocytic infiltration with patchy fibrosis suggestive of stage 4 Lupus nephritis

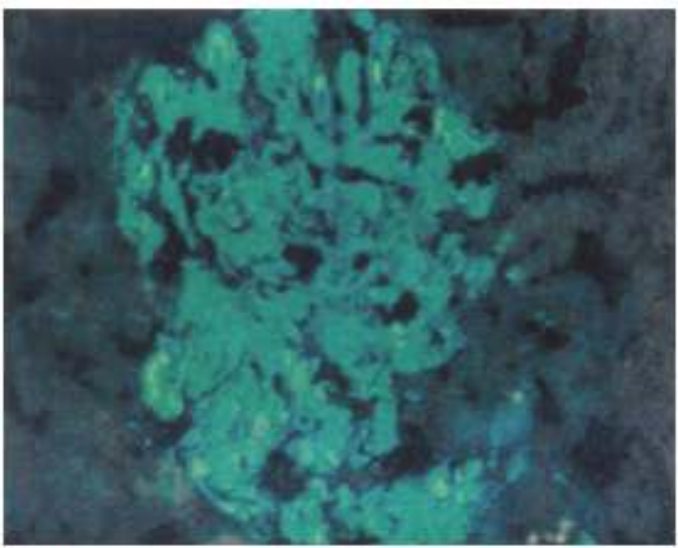

Figure 4: Same patient; Immuno-fluorescence microscopy showing peripheral coarse granular deposits of IgA (2+), IgG (3+), IgM $(1+)$, C3c (1+), C1q (1+) in all glomeruli i.e.; full house' suggestive of Lupus nephritis

Among the $11 \mathrm{LN}$ cases, 7 (63.6\%) children had non-nephrotic range proteinuria. Seven of these 11 cases were in Stage-IV (Figure 3 and 4), three had Stage-III LN and one case had Stage-V LN as per the ISN/RPS staging system. The clinicopathological correlation of these $\mathrm{LN}$ cases is as shown in Table 4. 
Table 4: Clinico-pathological characteristics of Lupus nephritis in our study (n=11)

\begin{tabular}{|c|c|c|c|c|c|}
\hline Feature at biopsy & \multicolumn{3}{|c|}{ Histopathological class } & p value & Significance \\
\hline & III $(n=3)$ & IV $(n=7)$ & $V(n=1)$ & & \\
\hline Hypertension $(n=11)$ & 3 & 7 & 1 & $<0.05$ & YES* \\
\hline Haematuria $(\mathrm{N}=11)$ & 3 & 7 & 1 & $<0.05$ & YES* \\
\hline $\begin{array}{l}\text { Nephrotic range proteinuria } \\
(\mathrm{n}=4)\end{array}$ & 0 & 4 & 0 & $<0.05$ & YES* \\
\hline $\begin{array}{l}\text { Non-nephrotic range } \\
\text { Proteinuria }(\mathrm{n}=11)\end{array}$ & 3 & 3 & 1 & $>0.05$ & $\mathrm{NO}^{* *}$ \\
\hline
\end{tabular}

*Class IV v/s Class III+V; **Class III v/s Class IV+V

Four cases finally had AKI subsequently. 27 $(19.85 \%)$ cases presented with nephritic syndrome of which 3 had RPGN which required aggressive management. $7.35 \%$ children had AKI and 3 children had CKD at the time of biopsy. Out of 3 CKD cases, 2 had CKD Stage-II (classified based on Glomerular filtration rate) and were treated conservatively.

\section{Discussion}

There is still an ongoing debate regarding the practice patterns of doing paediatric renal biopsy. Filler and associates form Canada reviewed 17 years data of paediatric renal biopsy. They concluded that in spite of reports of increasing incidence of FSGS, there is no reason to change the initial therapy and current indications to perform renal biopsy in children ${ }^{2,14}$. The clinical presentation of childhood glomerular diseases may vary from one patient to another. On the other hand the same clinical presentation may be associated with different glomerular diseases ${ }^{15}$. There is a definite need to know the clinical presentation, management guidelines and a good follow up of patients affected by these conditions by formation an individualised hospital registry. Since very few studies have occurred in this part of our country till now, we decided to analyse our data and form compact evaluation guidelines to provide the best care possible. Our study is in disagreement with studies from Turkey ${ }^{16}$, Croatia ${ }^{17}$ and Jamaica ${ }^{18}$ in acceptance with earlier studies from $\mathrm{Iran}^{4}$ and India $^{19}$ with respect to most common histopathological diagnosis being MCD and most common indication for biopsy being nephrotic syndrome. The discrepancy in the reported frequencies of MCD and FSGS from one series to the other could be related to renal biopsy policy, sample size, genetic makeup, geographic region and the nature of disease distribution. For centres where biopsy is performed only in children who are steroid resistant or steroid dependent this results in less frequent number of MCD patients undergoing renal biopsy. Therefore MCD is probably underrepresented in most of the series; resulting in the observed relative increase in the diagnosis of FSGS among the submitted biopsies ${ }^{20}$. The younger the child at onset (with the exception of the first few months of life), the greater is the likelihood that the lesion is MCNS. Since patients with MCNS have the highest rate of responsiveness to standard treatment and best long-term prognosis, the separation of MCNS from others is important $21,22,23$. In our study, MCD was the most common biopsy proven glomerular disease and nephrotic syndrome was most frequent clinical presentation. On the other hand, SLE is often more severe and difficult to treat in children than MCNS. Renal disease is very common in SLE, with clinical symptoms of renal involvement occurring in 30\%$70 \%$ of SLE patients ${ }^{24}$. In a study by Brunner et al on renal biopsy findings of paediatric SLE, they found that Class IV occurs in 40 to $60 \%$ of total LN cases, Class III in 10 to $20 \%$ and Class V in 3 to $28 \%$ children ${ }^{25}$. Nephrotic syndrome and hypertension correlate well with class IV LN as shown in various studies $26,27,28$. The mostappropriate treatment for optimal efficacy with minimal side-effects depends on the disease severity in $\mathrm{LN}^{29}$.

\section{Conclusions}

In our study, MCD was the most common biopsy proven glomerular disease and NS was most frequent clinical presentation. The best clinicopathological correlation was seen with lupus nephritis cases.

\section{References}

1. Nachman PH, Jennette JC, Falk RJ. Primary glomerular disease. In: Brenner BM, editors. Brenner and Rector's The Kidney. 8th ed. Philadelphia: Saunders; 2008. pp. 1101-91.

2. Absar, M. Diamond, Y. Sonia et al; Ten year experience of paediatric kidney biopsies from a single centre in Pakistan; Indian Journal of Nephrology 2010; 20(4): 190-2. http://dx.doi.org/10.4103/0971-4065.73446

3. Garg AK, Kanitkar M, Venkateshwar V; Medical Journal Armed Forces India 2010; 66(3): 216-9. http://dx.doi.org/10.1016/S03771237(10)8004 $\underline{0-1}$ 
4. Madani A, Fahimi D, Esfehani ST, Mohsseni P, Atayee N, Ahmadi M, et al. Glomerular Disease In Iranian Children: Clinicopathological Correlations. Pediatric Nephrology 2003; 18:925-8.

http://dx.doi.org/10.1007/s00467-003-1166-5

5. Shimada M, Araya C, Rivard C, Ishimoto T, Johnson RJ, Garin EH; Minimal change disease: a "two-hit" podocyte immune disorder?; Pediatric Nephrology 2011; 26(4): 645-9.

$\underline{\text { http://dx.doi.org/10.1007/s00467-010-1676-x }}$

6. Golay V, Trivedi M, Abraham A, Roychowdhary A, Pandey R; The spectrum of Glomerular diseases in a single centre: A clinic pathological correlation; Indian Journal of Nephrology 2013; 23(3): 168-75. http://dx.doi.org/10.4103/0971-4065.111833

7. Eddy AA, Symons JM; Nephrotic syndrome in childhood. Lancet 2003; 362(9384):629-39. http://dx.doi.org/10.1016/S01406736(03)1418 $\underline{4-0}$

8. Pais P, Avner ED. Nephrotic syndrome. In: Kliegman RM, Stanton BF, St. Geme JW III, Schor NF, Behrman RE. Nelson Textbook of Pediatrics. 19th ed. Philadelphia, Page 18031806: Saunders Elsevier; 2011.

9. Bagga A, Mantan M; Nephrotic syndrome in children; Indian Journal of Medical Research 2005; 122(1):13-28.

10. Avner ED, Harmon WE, Niaudet $\mathrm{P}$ et al; Paediatric nephrology; $6^{\mathrm{TH}}$ edition, SpringerVerlag Berlin Heidelberg 2009, volume 1, page no. 746 .

11. Bagga A, Jain R, Vijayakumar M, Kanitkar M, Ali U; Evaluation and management of Hypertension; Indian Pediatrics 2007; 44:10321.

12. Markowitz GS, D'Agati VD; The ISN/RPS 2003 classification of lupus nephritis: An assessment at three years; Kidney International 2007; 71, 491-5. http://dx.doi.org/10.1038/sj.ki.5002118

13. Austin HA, Muenz LR, Joyce KM, Antonovych TA, Balow JE. Diffuse proliferative lupus nephritis: identification of specific pathologic features affecting renal outcome. Kidney International 1984; 25:68995.

http://dx.doi.org/10.1038/ki.1984.75
14. Filler G, Young E, Geier P, Carpenter B, Drukker A, Feber J. Is there really an increase in non-minimal change nephrotic syndrome in children? American Journal of Kidney Disease 2003; 42:1107-13. http://dx.doi.org/10.1053/j.ajkd.2003.08.010

15. Shrestha P, Bhatta NK,Tiwari A et al; Glomerular Diseases in Children - A Review of 27 Cases recorded at a Single Centre in Eastern Nepal; Journal of the Nepal Paediatric Society 2009; 29 (1): 26-9. http://dx.doi.org/10.3126/jnps.v29i1.1597

16. Bircan Z, Yavuz Yilmaz A, Katar S, Vitrinel A, Yildirim M. Childhood idiopathic nephrotic syndrome in Turkey. Pediatric International 2002; 44:608-11.

http://dx.doi.org/10.1046/j.1442200X.2002.01 $\underline{628 . x}$

17. Bazina M, Glavina-Durdov M, ScukaenecSpoljar M, Bazina A, Vukojevic K, Ljutic D, et al. Epidemiology of Renal Disease in Children in the region of Southern Croatia: A 10 Year Review of Regional Renal Biopsy Database. Medical Science Monitor. 2008; 134:172-6.

18. Gooden M, Miller M, Shah D et al; Clinicopathological features of atypical nephrotic syndrome in Jamaican children; West Indian Medical Journal 2010; 59(3):319-24.

19. Nammalwar BR, Vijayakumar M, Prahlad N. Experience of renal biopsy in children with nephrotic syndrome. Pediatric Nephrology 2006; 21:286-8. http://dx.doi.org/10.1007/s00467-005-2084-5

20. Jalalah SM, Jamal AA. Childhood primary glomerular diseases in the western region of Saudi Arabia Saudi Journal of Kidney Disease and Transplantation 2009; 20:608-12.

21. Bagga A. Management of steroid sensitive nephrotic syndrome. Revised guidelines: Indian Pediatrics 2008; 45(3):203-14.

22. Ozkaya N, Cakar N, Ekim M, Kara N; Primary nephrotic syndrome during childhood in Turkey; Pediatric International 2004; 46(4):436-8. http://dx.doi.org/10.1111/j.1442200x.2004.019 $\underline{20 . x}$ 
23. Bircan Z, Yilmaz AY, Katar S, Yildrim M. Childhood idiopathic nephrotic syndrome in Turkey. Pediatric International 2002; 44:60813.

http://dx.doi.org/10.1046/j.1442200X.2002.01 $\underline{628 . x}$

24. Mina R, Von Scheven E, Ardoin SP, Eberhard BA, Punaro $\mathrm{M}$, Ilowite $\mathrm{N}$ et al. Consensus treatment plans for induction therapy of newly diagnosed proliferative lupus nephritis in juvenile systemic lupus erythematosus. Arthritis Care Res (Hoboken) 2012; 64(3): 375-83.

http://dx.doi.org/10.1002/acr.21558

25. Marks SD, Sebire NJ, Pilkington C, Tullus K. Clinicopathological correlations of pediatric lupus nephritis. Pediatric Nephrology 2007; 22(1):77-83.

http://dx.doi.org/10.1007/s00467-006-0296-y
26. Cameron JS. Lupus nephritis in childhood and adolescence. Pediatric Nephrology 1994; 8:230-49.

http://dx.doi.org/10.1007/BF00865490

27. Bogdanović R, Nikolić V, Pasić S et al. Lupus nephritis in childhood: a review of 53 patients followed at a single center. Pediatric Nephrology 2004; 19:36-44. http://dx.doi.org/10.1007/s00467-003-1278-y

28. Emre S, Bilge I, Sirin A et al. Lupus nephritis in children: prognostic significance of Clinicopathological findings. Nephron 2001; 87:11826.

http://dx.doi.org/10.1007/s00467-003-1278-y

29. Henderson L, Masson P, Craig JC, Flanc RS et al. Treatment for lupus nephritis. Cochrane Database Syst Rev. 2012 Dec 12; 12:CD002922. 